\title{
O001: Getting the unexpected: no association between hand hygiene and workload
}

\author{
S Scheithauer ${ }^{1,2^{*}}$, M Dangel $^{1}$, B Batzer ${ }^{1}$, C Pino Molina ${ }^{3}$, A Widmer $^{1}$ \\ From 2nd International Conference on Prevention and Infection Control (ICPIC 2013) \\ Geneva, Switzerland. 25-28 June 2013
}

\section{Introduction}

A high compliance with hand hygiene is a cornerstone of any infection control program. However, a high workload and a lack of time are most commonly used argues against an appropriate compliance.

\section{Objectives}

In order to assess the relationship between the hand hygiene events (HHE) and the workload, we correlated HHEs per patient-day (PD) with the staff time/PD (h), the nursing effort/PD (h) and the C-value indexing the workload, respectively.

\section{Methods}

All HHEs at a hematology ward (University Hospital Basel, Switzerland) were continuously recorded from 01.03.12 to 28.02.213 using the Ingo-man Weco (Ophardt Hygienetechnik, Issum; Germany) and could be analyzed dispenser-, day-, shift-, localization-specifically. Daily data on patients, staff time (h), nursing effort (h), C-value ( 1 - (nursing effort / weighted staff time) "100) were calculated with regard to the workday from the electronic patient documentation sheets. For statistics SPSS was used.

\section{Results}

During the one year investigation 208.184 HHE translating into $57( \pm 10) \mathrm{HHE} / \mathrm{PD}$ were performed. HHE from Monday to Friday exceeded HHE during the weekends with $59( \pm 10)$ versus $51( \pm 9) /$ PD. HHE/PD were significantly associated with the staff time with $\mathrm{r}=0.37$ $(\mathrm{p}=0.01)$ and with the nursing effort with $\mathrm{r}=0.41$ $(\mathrm{p}=0.01)$, respectively. These associations could be verified during workdays as well as during the weekends. In contrary, HHE/PD did not depend on workload in general indexed by the $\mathrm{C}$-value with $\mathrm{r}=-0.04$. However, during Monday and Friday HHE/PD seemed to correlate even inversely with the $\mathrm{C}$-value $(\mathrm{r}=0.20 ; \mathrm{p}=0.01)$.

\section{Conclusion}

HHE/PD were associated with the staff time and the nursing effort indicating a constant compliance regardless the workload. This hypothesis was confirmed by the lack of a positive association between the $\mathrm{C}$-value and the HHE/PD. Thus compliance seemed not to be affected by workload at the hematology ward enrolled in this investigation.

\section{Disclosure of interest}

None declared.

\section{Author details}

${ }^{1}$ Infection Control, University Hospital Basel, Basel, Switzerland. ${ }^{2}$ Infection Control \& Infectious Diseases, University Hospital Aachen, RWTH Aachen, Aachen, Germany. ${ }^{3}$ Hematology, University Hospital Basel, Basel, Switzerland.

\section{Published: 20 June 2013}

\section{doi:10.1186/2047-2994-2-S1-O1}

Cite this article as: Scheithauer et al:: 0001: Getting the unexpected: no association between hand hygiene and workload. Antimicrobial

Resistance and Infection Control 2013 2(Suppl 1):01. 